\title{
Effects of Thermal Ageing in $\beta$-Phase in Cu-Al-Ni Single Crystals
}

\author{
C. Picornell, J. Pons and E. Cesari \\ Departament de Física, Universitat de les Illes Balears, Cra de Valldemossa km 7,5, \\ 07071 Palma de Mallorca, Spain
}

\begin{abstract}
The effect of isothermal ageing of $\beta-\mathrm{Cu}-\mathrm{Al}-\mathrm{Ni}$ alloys at low temperatures (473K and $573 \mathrm{~K}$ ) on the martensitic transformation has been studied using differential scanning calorimetry and transmission electron microscopy. Three single crystals with different Al content $(13.5,13.6$ and $13.8 \mathrm{wt} \%$ ) and the same $\mathrm{Ni}$ concentration (4\%) were used. Before ageing, the samples were annealed at $1070 \mathrm{~K}$ and quenched to room temperature. The transformation temperatures remained nearly constant during the initial stages of ageing and started to increase noticeably after a given ageing time, which is shorter in the samples with higher Al content. For the alloy with highest Al content, the Ms decreased slightly at the beginning of ageing at 473K. The transformation to two coexisting martensitic structures, $\beta^{\prime}(18 \mathrm{R})$ and $\gamma^{\prime}(2 \mathrm{H})$ has been observed. The proportion of each one changes with the composition and ageing, the $\gamma^{\prime}$ phase being promoted for increasing ageing times and temperatures. A good correlation exists between the initial ageing stage, in which there is no evolution of transformation temperatures, with the coexistence of the two martensites. The formation of the two kinds of martensites is related to the short range reordering processes taking place during ageing, specially of as quenched next nearest neighbours disordered $\mathrm{Cu}-\mathrm{Al}$ pairs. The results would indicate that the disordered $\mathrm{Cu}-\mathrm{Al}$ pairs stabilize the $\beta^{\prime}$ martensite and when these pairs recover the correct positions, the $\gamma^{\prime}$ becomes the stable martensite. The high increase of transformation temperatures with ageing at $573 \mathrm{~K}$ is related to two different precipitation processes observed.
\end{abstract}

\section{INTRODUCTION}

$\mathrm{Cu}$-based shape memory alloys are susceptible to post-quench ageing effects. In the case of $\mathrm{Cu}-\mathrm{Al}-\mathrm{Ni}$ alloys aged in the $\beta$ phase, a continuous increase of transformation temperatures (although in some cases this is preceded by a slight decrease) has usually been observed. It has been explained in terms of short range atomic ordering processes and also in terms of precipitation of stable phases (usually $\gamma$ phase). After more prolonged ageing a big degradation of the transformation caused by the precipitates is observed [1-5]. Rodriguez and Guénin [4] observed a very fine precipitation process being progressively developed during ageing at $623 \mathrm{~K}$, and attributed the continuous increase of transformation temperatures during the first stages of ageing to the very beginning of this fine precipitation process. On the other hand, for several $\mathrm{Cu}-\mathrm{Al}-\mathrm{Ni}$ alloys a transformation to a mixture of two martensitic phases $\left(\beta^{\prime}\right.$ and $\left.\gamma^{\prime}\right)$ has been reported [68]. Just after quenching from high temperatures (in the $\beta$ stability region) the $\beta^{\prime}$ has been observed to be preferentially formed, while after ageing in the parent phase the $\gamma^{3}$ martensite is progressively favoured. In the present paper, a study of the transformation behaviour during ageing at $473 \mathrm{~K}$ and $573 \mathrm{~K}$ for three alloys with compositions similar to those showing a double transformation, complemented with microstructural observations, will be presented and discussed. 


\section{EXPERIMENTAL}

Three monocrystalline alloys with different aluminium content have been used in this study. The composition of the alloys and their temperatures for the martensitic transformation start, Ms, are shown in table 1 . Prior to ageing, the samples were submitted to a reference heat treatment consisting of annealing in the $\beta$-phase at $1070 \mathrm{~K}$ for $15 \mathrm{~min}$ followed by a quench in water at room temperature. The thermally induced martensitic structure obtained before ageing is also shown in Table 1. Afterwards, the samples were aged, in the $\beta$ phase, in a melted salt bath at 473 or $573 \mathrm{~K}$ for different intervals of time between 6 and $2.610^{5} \mathrm{~s}$ and quenched again in water at room temperature. The reference thermal treatment was performed before each ageing time, except in a sample of alloy 3 , in which the evolution of the transformation with the ageing time at $473 \mathrm{~K}$ was studied by accumulating successive ageing time periods after a single initial annealing thermal treatment. Additionally, several samples of alloy 3 were aged at 473 $\mathrm{K}$ in a Perkin Elmer DSC7 calorimeter, at nominal heating and cooling rates of $200 \mathrm{~K} / \mathrm{min}$ to and from that temperature.

Table 1. Composition (in wt\%), Ms temperature and thermally induced martensitic phase obtained without any ageing time, for each studied alloy .

\begin{tabular}{|c|c|c|c|c|c|}
\hline Alloy & $\mathrm{Cu}$ & $\mathrm{Al}$ & $\mathrm{Ni}$ & $\mathrm{Ms}, \mathrm{K}$ & phase \\
\hline 1 & 82.5 & 13.5 & 4.0 & 345 & $\beta^{\prime}$ \\
\hline 2 & 82.4 & 13.6 & 4.0 & 309 & $\beta^{\prime}$ \\
\hline 3 & 82.2 & 13.8 & 4.0 & 277 & $\gamma^{\prime}+\beta^{\prime}$ \\
\hline
\end{tabular}

The characteristics of the martensitic transformation were studied by means of Differential Scanning Calorimetry. Some heating runs were extended to $873 \mathrm{~K}$ in order to determine the L2 $2_{1}$ ordering transition temperature, which resulted to be $\sim 760 \mathrm{~K}$.

Microstructural determinations were performed by transmission electron microscopy (TEM, Hitachi $\mathrm{H} 600$ at $100 \mathrm{kV}$ ). Discs of $5 \mathrm{~mm}$ diameter and $1.5 \mathrm{~mm}$ thickness (the same dimensions as the DSC samples) were submitted to the reference and ageing thermal treatments. From these discs, TEM specimens were prepared by means of mechanical and twin jet electrolytic polishing in a solution of $15 \%$ nitric acid in methanol.

\section{EXPERIMENTAL RESULTS}

\subsection{Calorimetric results}

The effect of alloy composition on the transformation temperatures can be seen in table 1 . After the initial thermal treatment, the alloys 1 and 2 show a single-peak thermogram on cooling and heating, corresponding to a $\beta \leftrightarrow \beta^{\prime}$ direct and reverse transformation, respectively. Nevertheless, after ageing at 473 or $573 \mathrm{~K}$, a single direct transformation and a two-stage reverse transformation can be distinguished, which corresponds to a simultaneous transformation to the $\beta^{\prime}$ and $\gamma^{\prime}$ martensites (18R and $2 \mathrm{H}$ structures, respectively) on cooling. The two martensitic structures have indeed been observed by TEM and electron diffraction in different zones of the same sample. The reverse transformation takes place separately due to the higher hysteresis of the $\beta \leftrightarrow \gamma^{\prime}$ transformation, thus the $\gamma^{\prime}$ retransforms at higher temperatures. A similar behaviour was already observed in this alloy system with similar compositions [6-8] and also in $\mathrm{Cu}-\mathrm{Zn}-\mathrm{Al}-\mathrm{Mn}$ alloys [9]. The relative amount of both kinds of martensite formed in a transformation cycle can be estimated, in a first approximation, by the relative area of the two DSC peaks obtained on heating. Doing so, it is found that the amount of ' $\gamma^{\prime}$ martensite is very small at the beginning of ageing, the transformation being almost completely to the $\beta$ ' phase. For longer ageing times the peak corresponding to the $\beta^{\prime}$ phase decreases continuously with ageing time and consequently, the one corresponding to the $\gamma^{\prime}$ phase increases. After a certain ageing time the $\beta^{\prime}$ peak has disappeared completely and all the material transforms to the $\gamma^{\prime}$ phase (figure 1). Two regimes can be distinguished in the transformation temperatures evolution curves (figure 2): a first stage in which the temperatures do not show a clear evolution and a second stage in which they increase continuously with ageing time. Good correlation exists between the 
boundary of the two stages with the $\beta^{\prime}$ peak disappearance, i.e. when the $\beta^{\prime}$ and $\gamma^{\prime}$ martensites coexist the transformation temperatures do not show any defined evolution, they start to clearly increase when only a single martensite is formed. This behaviour holds for the ageing at 473 and $573 \mathrm{~K}$, but in the latter case the kinetics is faster: the $\beta^{\prime}$ phase disappears at shorter ageing times and the transformation temperatures increase earlier. This fact indicates that the promotion of $\gamma^{\prime}$ martensite during ageing is a thermally activated process. From the data shown, together with the results of additional ageings at $373 \mathrm{~K}$ performed on alloy 3 (which present the same trends as those commented above), an activation energy of $0.29 \mathrm{eV}$ has been obtained. This is, however, only a rough estimation since data from only three ageing temperatures have been used.

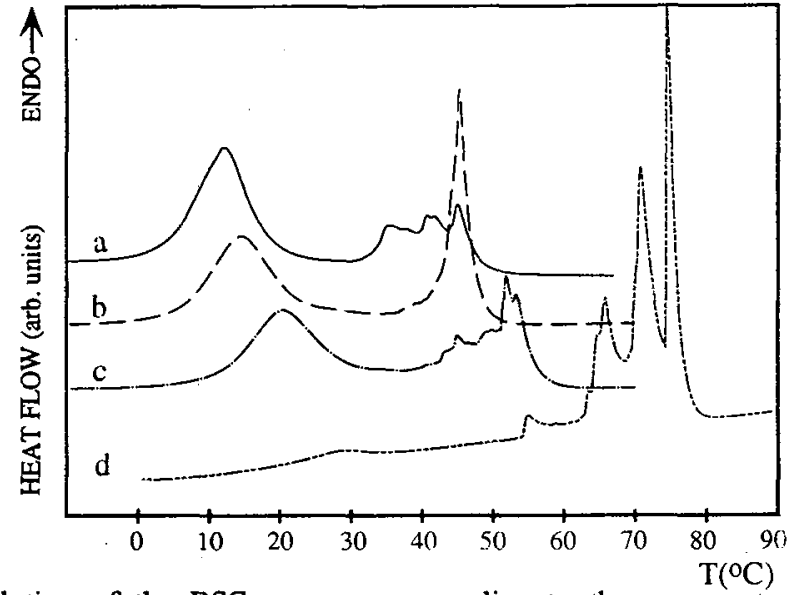

Figure 1. Evolution of the DSC curves corresponding to the reverse transformation after different ageing times at $473 \mathrm{~K}$; a) $200 \mathrm{~s}$; b) $2 \mathrm{ks}$; c) $5 \mathrm{ks}$; d) $12.5 \mathrm{ks}$. As can be observed, the amount of $\gamma^{\prime}$-phase increases with ageing time, at the expense of the $\beta^{\prime}$ phase.

It is worth noting that the proportion of the two martensites appearing on cooling is very sensitive to the way the thermal treatment is done. This has been studied mainly for alloy 3 aged at $473 \mathrm{~K}$. In figure $2 \mathrm{c}$ different symbols have been used to distinguish the way to perform the ageing treatment. The faster evolution to a single $\gamma^{\prime}$ martensitic structure observed in the case of upquenching into the melted salt bath is probably due to the higher concentration of vacancies available at the beginning of ageing. In the case of ageing inside the calorimeter, some of the vacancies retained by the initial quench from $1070 \mathrm{~K}$ are recombined during the relatively long heating time required to reach the ageing temperature, compared to the case of upquenching into the melted salt bath. Thus, these results could indicate that the promotion of $\gamma^{\prime}$ martensite at the expense of $\beta$ ' is a diffusional process assisted by vacancies. Comparing the results of the three alloys, it is interesting to note that the first ageing stage (coexistence of two martensitic phases) is shorter as the $\mathrm{Al}$ content increases. For alloy 3, with the highest aluminium content, the martensitic phase formed after the reference thermal treatment and before ageing is already of the $\gamma^{\prime}$ type for the most part $(\sim 85 \%)$, with a relatively small amount of $\beta^{\prime}$ phase.

Concerning the transformation temperatures of alloy 3 , it has been observed that the Ms evolution for each way to perform the ageing treatment at $473 \mathrm{~K}$ displays a slight decrease by less than $10 \mathrm{~K}$ followed by a further increase, then showing a minimum at about 200s ageing time. This behaviour, also observed by ageing at $373 \mathrm{~K}$, is not present in the curve corresponding to ageing at $573 \mathrm{~K}$. A similar behaviour (first decrease and further increase of $\mathrm{Ms}$ ) has been also reported in refs $[3,4]$ only for ageing temperatures in the range from $453 \mathrm{~K}$ to $473 \mathrm{~K}$. Considering the whole set of data from all ageings at $473 \mathrm{~K}$, plotted in figure $2 c$, a rather big dispersion of points exists in the first ageing stages, but among the dispersion the lower transformation temperatures correspond systematically with the cases in which a higher fraction of $\beta^{\prime}$ martensitic phase is formed on cooling. Thus, an interesting conclusion can be made: when the coexistence of the two martensites takes place, the transformation temperatures are, in general, slightly lower than in the cases when, for equivalent ageing times, a highly predominant or a single martensite is formed. 


\subsection{Microstructural determinations}
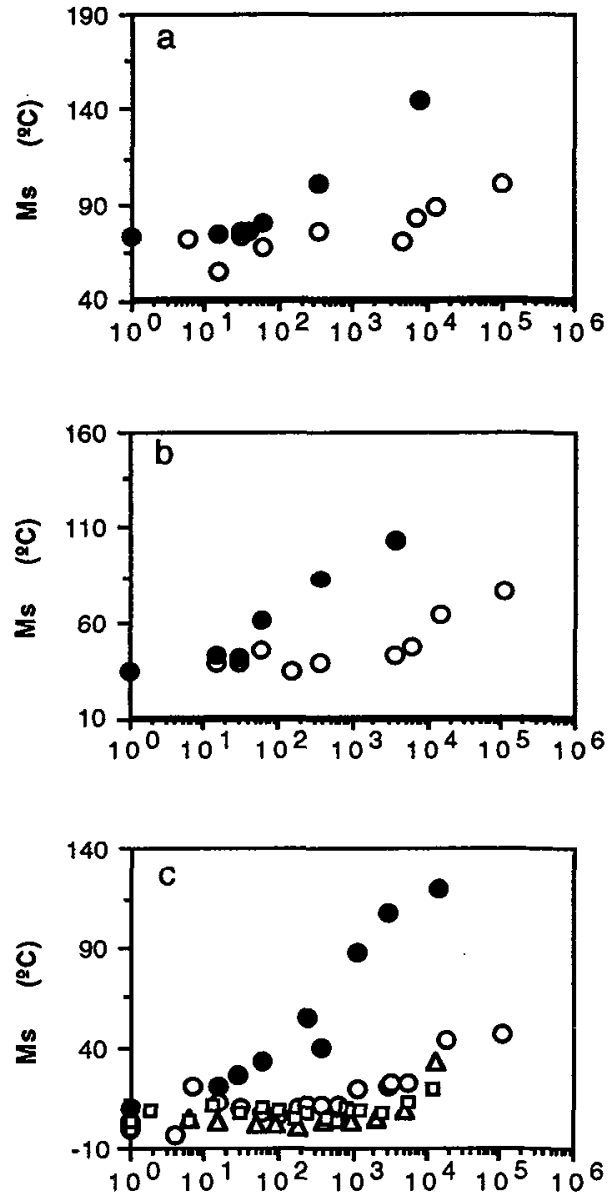

Ageing time

(s)
As mentioned above, the coexistence in the same sample of $\beta^{\prime}$ and $\gamma^{\prime}$ martensites for short ageing times, and only $\boldsymbol{\gamma}^{\prime}$ for longer ones has been confirmed by electron diffraction. A systematic study of the B2 and $L 2_{1}$ ordered domains and antiphase boundaries at different ageing times has been performed, in order to check their relationship with the observed ageing effects. Nevertheless, the size and shape of both kinds of domains (shown in figure 3) do not show any clear evolution. This rules out an explanation of the ageing effects on the martensitic transformation in terms of long range ordering processes.

For alloys 1 and 3 , the as-quenched samples and also those aged at $473 \mathrm{~K}$ up to $10^{5} \mathrm{~s}$ do not show any presence of visible precipitates. Distributions of cuboidal $\gamma$ phase precipitates have been observed only for relatively long ageing times at 573K (see figure 4), increasing in size as the ageing proceeds. In alloy 2, however, this kind of precipitates has already been observed after the initial quench from $1070 \mathrm{~K}$. In all samples, a second decomposition process takes place concurrently, although it is only made evident after very long ageing times at $573 \mathrm{~K}$. It consists of a very fine and dense precipitation process (sizes of a few $\mathrm{nm}$ ), more densely accumulated at the $\mathrm{L} 21_{1}$ antiphase boundaries (figure 5). For shorter ageing times, only a blurred contrast of the martensite is visible, the size of these fine precipitates being too small to be distinguished.

\section{DISCUSSION}

The observation that a part of the specimen transforms to $\beta^{\prime}$ martensite and the rest to $\gamma^{\prime}$ indicates that the stability of both martensitic phases is very close. Nevertheless, the obtaining of only $\gamma^{\prime}$ after ageing shows that this structure is the

Figure 2. Evolution of Ms during ageing at $473 \mathrm{~K}$ (open symbols) and 573K (full symbols) for alloy 1 (a), alloy 2 (b) and alloy 3 (c).

$\mathrm{O}$ : one step ageing in the melted salt bath.

$\Delta$ : accumulated ageing in the melted salt bath.

ageing performed in the calorimeter. most stable at the present composition ranges, with relatively high concentration of $\mathrm{Al}$, as is already known for compositions with a high electron to atom ratio. In the present case, this fact is well reflected in the observation that shorter ageing times are required to obtain the single transformation to $\gamma^{\prime}$ martensite in the Al richer alloys.

After quenching from $1070 \mathrm{~K}$, an $\mathrm{L} 22_{1}$ structure with a considerable short range disorder is obtained. Our results seem to indicate that the coexistence of $\beta^{\prime}$ and $\gamma^{\prime}$ martensite can be related to the short range disorder retained after quenching from 1070K. The present results, showing no changes in the ordered domains, rule out a long range order process. The subsequent reordering during ageing (recovery of the short range disorder) promotes the formation of $\gamma^{\prime}$ martensite. This conclusion is in agreement with the suggestion of Sakamoto and Shimizu that the ordering favours the most close packed structures [7]. A recent study using the ALCHEMI technique [10] has shown that the short range disorder comes mainly 
from $\mathrm{Cu}-\mathrm{Al}$ pairs with swapped positions in relation to the next nearest neighbour ordered structure, the $\mathrm{Ni}$ atoms not playing any direct relevant role. Thus, at the present composition ranges, the relative stability of $\beta^{\prime}$ and $\gamma^{\prime}$ phases seems to be controlled by the $\mathrm{Cu}$-Al pairs. The disordered pairs stabilize the $\beta$ ' martensite, and when these pairs recover the "correct" positions, the $\gamma^{\prime}$ becomes the stable martensitic phase. This is supported by the above mentioned indications that the promotion of $\gamma^{\prime}$ martensite is a diffusionally controlled process assisted by vacancies. At this point, it is worth noting that the value obtained for the activation energy of this process is lower than the values for the vacancy migration given in the literature $(0.30 \mathrm{eV}[11], 0.76 \mathrm{eV}[12], 0.65[13], 0.68$ [14]), although these values have been measured for $\mathrm{Cu}-\mathrm{Zn}-\mathrm{Al}$ alloys. The first value of this list $(0.30 \mathrm{eV})$ is very close to the value obtained in the present work, but it seems not to be a good reference since it is very discrepant with the rest of the values and, moreover, it was obtained by a less efficient experimental device than in ref. [12], as commented in the latter work.
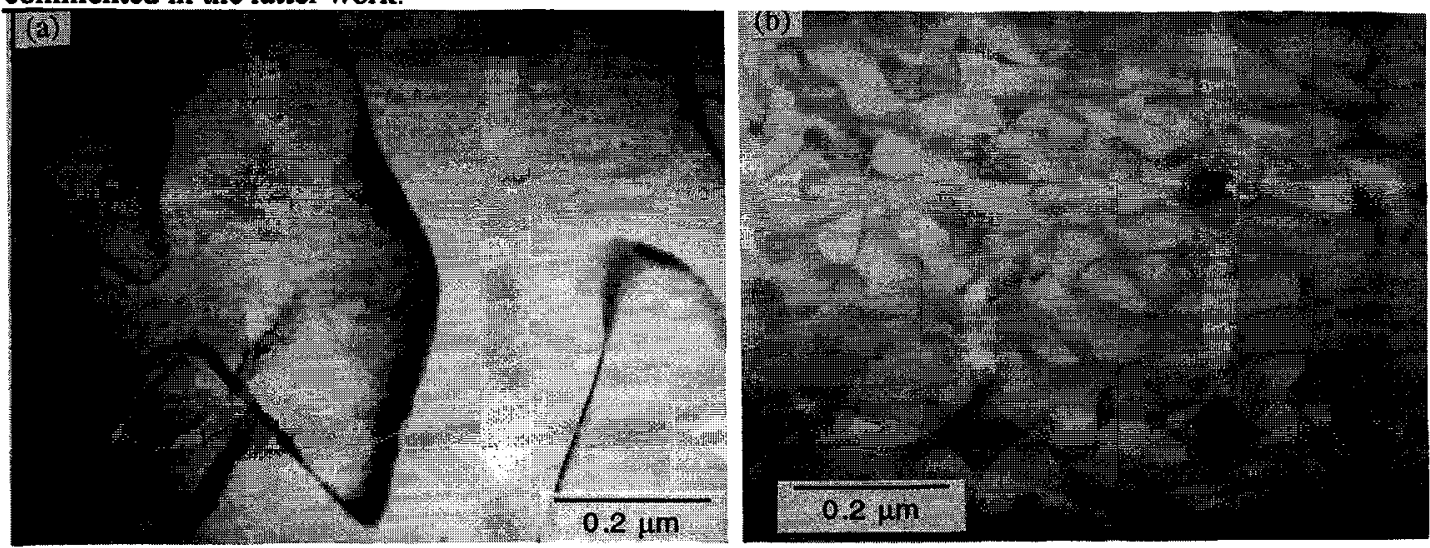

Figure 3. B2 (a) and L21 (b) ordered domains and antiphase boundaries observed in a sample of alloy 3 aged $1 \mathrm{ks}$ at $473 \mathrm{~K}$.

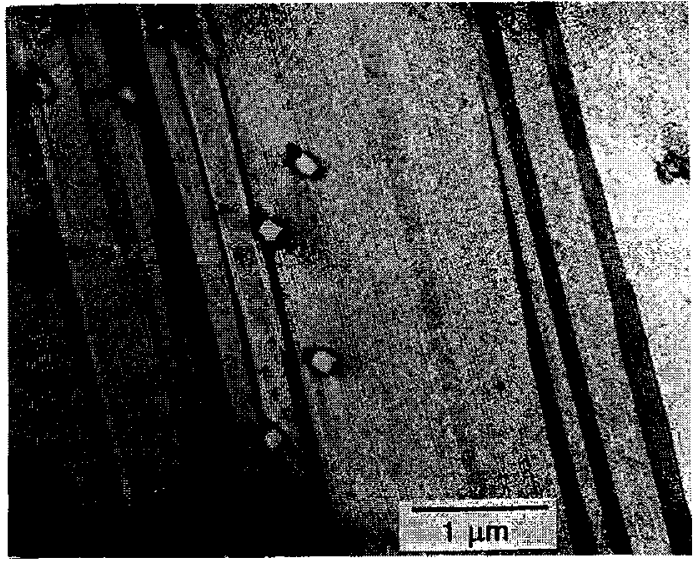

Figure 4. $\gamma$-phase precipitates obtained after 3 ks ageing at 573K in a sample of alloy 3.

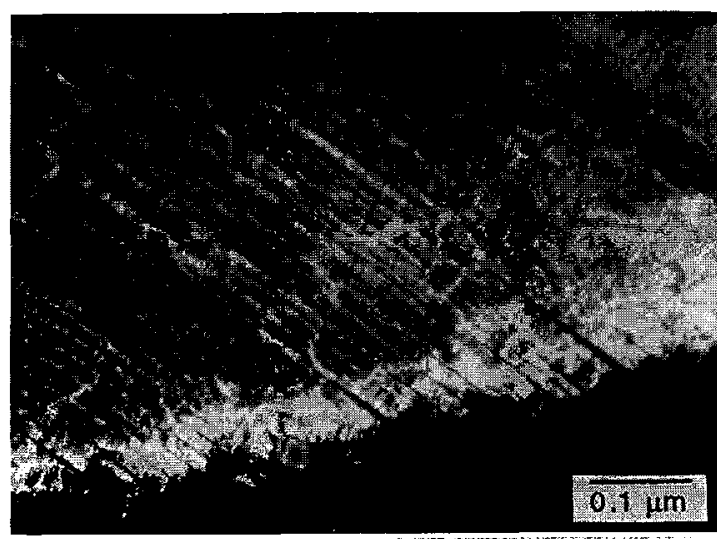

Figure 5. Dense precipitates observed in a sample of alloy 3 aged $7.2 \mathrm{ks}$ at $573 \mathrm{~K}$.

Concerning the transformation temperatures, their evolution is usually observed already from the very beginning of ageing in alloys transforming to a single martensitic phase [1-4]. Usually, the temperatures have been observed to increase, which has been related to the next nearest neighbour reordering [2-4], al though in low temperature ageings a previous slight decrease (related to nearest neighbour reordering) has been reported $[3,4]$. In the present results, a stage with no evolution of transformation temperatures, coincident with the coexistence of $\beta^{\prime}$ and $\gamma^{\prime}$ martensites, is obtained. In this case, the accommodation of both types of martensite requires an extra elastic energy which tends to decrease the transformation temperature range. This is supported by the systematic observation of lower Ms values in samples 
transforming to both martensites in relation to samples with similar thermal treatments but transforming in a greater part to $\gamma^{\prime}$. Evidence of difficulties in the accommodation of both martensites have also been reported in [9]. Thus, at the first stages of ageing, a competition between the reordering processes and the coexistence of two martensites seems to hold, giving rise to an undefined evolution of transformation temperatures.

A fine precipitation process very similar to the one described above was observed by Rodriguez and Guénin [4] by means of TEM and low angle X-ray scattering, which after a more prolonged ageing finished in a degradation of the transformation characteristics. The authors related the very beginning of this decomposition process to the increase of transformation temperatures observed at relatively short ageing times. Concerning the present results, a continuous increase of transformation temperatures during ageing as high as $100 \mathrm{~K}$ seems very large to be attributed to short range reordering. No evolution of the ordered domains having been observed, a similar explanation as ref. [4] seems to hold, i.e., the continuous increase of transformation temperatures observed during ageing at $573 \mathrm{~K}$ can probably be associated to this fine precipitation process, and also to the $\gamma$ phase precipitates. It is worth noting that similar fine precipitation processes have been observed in $\mathrm{Cu}-\mathrm{Al}-\mathrm{Ni}-\mathrm{B}$ [15] and $\mathrm{Cu}-\mathrm{Al}-\mathrm{Ni}-\mathrm{Ti}$ [16], also accompanied by a continuous increase of transformation temperatures.

\section{Acknowledgements}

Partial financial support from DGES-MES, Spain (project num. PB95-0340) is gratefully acknowledged.

\section{References}

[1] Nakamura F., Kusui J., Shimizu Y., Takamura J.; J. of Jopan Inst. Met. 44 (1980) 1302

[2] Kennon N.F., Dunne D.P., Middleton L.; Met. Trans. A 13A (1982) 551

[3] Van Humbeeck J., Chandrasekaran M., Delaey L.; ISIJ International 29 (1989) 388

[4] Rodriguez P., Guénin G.; Mat. Sci. Eng. A129 (1990) 273

[5] Zárubová N., Gemperle A., Novák V.; "Initial stages of $\gamma_{2}$ precipitation in an aged Cu-Al-Ni SMA", submitted to Mater. Sci. Eng.

[6] Van Humbeeck J., Van Hulle D., Delaey L., Ortín J., Segui C., Torra V.; Trans. of The Japan Inst. of Metals 28 (1987) 383

[7] Sakamoto H., Shimizu K.; ISIJ International 29 (1989) 395

[8] Recarte V., Nó M.L., San Juan J.; J. Phyșique IV, Coll. C2, Vol. 5 (1995) 175

[9] Seguí C., Cesari E., Van Humbeeck J.; Mater. Trans. of Japan Inst. Metals 32 (1991) 898.

[10] Nakata Y., Tadaki T., Shimizu K.; Mater. Trans. of Japan Inst. Metals 31 (1990) 652

[11] Planes A., Macqueron J.L., Morin M., Guenin G.; Mat. Sci. Eng. 50 (1981) 53

[12] Elgueta J., Macqueron J.L., Planes A.; J. Phys: Condens. Matter 4 (1992) 285

[13] Rapacioli R.; Ph D. Thesis, Instituto Balseiro (1979)

[14] Van Humbeeck J., Segers D., Delaey L.; Scripta Metall. 19 (1985) 477

[15] Font J., Muntasell J., Pons J., Cesari E.; “Thermal cycling effects in high temperature Cu-Al-Ni-MnB shape memory alloys", J. Mater. Res. in press.

[16] Cesari E., Segui C., Pons J., Perelló F., "Internal friction and Young modulus behaviour of hot rolled $\mathrm{Cu}-\mathrm{Al}-\mathrm{Ni}$-Ti shape memory alloys", $J$, de Physique, in press. 